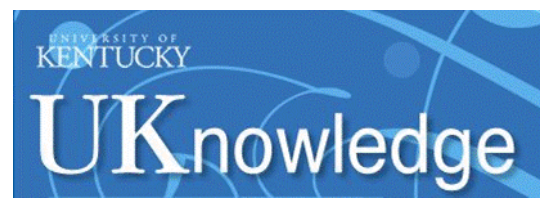

University of Kentucky

UKnowledge

\title{
Mobile Apps for Visual Research: Affordances and Challenges for Participant-Generated Photography
}

Sarah C. Barriage

University of Kentucky, sarah.barriage@uky.edu

Alison Hicks

University College London, UK

Follow this and additional works at: https://uknowledge.uky.edu/slis_facpub

Part of the Library and Information Science Commons

Right click to open a feedback form in a new tab to let us know how this document benefits you.

\section{Repository Citation}

Barriage, Sarah C. and Hicks, Alison, "Mobile Apps for Visual Research: Affordances and Challenges for Participant-Generated Photography" (2020). Information Science Faculty Publications. 92.

https://uknowledge.uky.edu/slis_facpub/92

This Article is brought to you for free and open access by the Information Science at UKnowledge. It has been accepted for inclusion in Information Science Faculty Publications by an authorized administrator of UKnowledge. For more information, please contact UKnowledge@lsv.uky.edu. 


\section{Mobile Apps for Visual Research: Affordances and Challenges for Participant- Generated Photography}

\section{Digital Object Identifier (DOI)}

https://doi.org/10.1016/j.lisr.2020.101033

\section{Notes/Citation Information}

Published in Library \& Information Science Research, v. 42, issue 3.

(c) 2020 Elsevier Inc.

(c) 2020. This manuscript version is made available under the CC-BY-NC-ND 4.0 license https://creativecommons.org/licenses/by-nc-nd/4.0/.

The document available for download is the authors' post-peer-review final draft of the article. 


\section{Mobile apps for visual research: Affordances and challenges for participant-generated photography.}

Barriage, S. \& Hicks, A. (2020). Mobile apps for visual research: Affordances and challenges for participant-generated photography. Library and Information Science Research, 42(3).

\section{Introduction}

The integration of participant-generated photography in research can be a powerful means of exploring emic perspectives and experiences. Within Library and Information Science (LIS), researchers are increasingly incorporating participant-generated photography into studies examining topics such as information needs, information seeking, and use of library space. Smartphones have played a key role in supporting this growing interest in participant-generated photography; increasing smartphone ownership (Pew Research Center, 2019) simplifies data collection while the portability of mobile devices facilitates access to a wide range of social and physical contexts. Smartphone usage also opens up visual research to the possibilities of employing apps, which are pieces of software that run on smartphones and other mobile devices (García, Welford \& Smith, 2016). Notwithstanding, the need for careful management of participant-centered studies calls for an interrogation of how mobile apps are employed within visual research methodologies. This methodological discussion examines the use of EthOS and PixStori, two mobile apps recently used in research that employed photo-elicitation methods to explore the information practices of children and young adults, to establish a research agenda for the continued exploration of mobile apps within participant-generated photographic research methods.

\section{Problem statement}

Mobile apps have a long history within LIS; the potential to provide personalized and targeted support has led researchers to develop and promote a wide range of digital portals (e.g., Buchanan, Jardine \& Ruthven, 2018). However, while researchers may view mobile apps as producing considerable value for end-users, there are few published discussions of their potential role as a research tool. This oversight is particularly problematic within visual research, which is already underpinned by a number of complex professional, practical and moral issues (Hicks \& Lloyd, 2018). Researchers' lack of engagement with the challenges of mobile apps runs the risk of exposing participants to harm by obscuring potential ethical concerns, as well as eliding other technical and social issues. At the same time, researchers' failure to examine the affordances of mobile apps may impede the effectiveness of these tools, including their potential role in addressing the practical management of visual research.

Subjecting mobile apps to critical scrutiny has the potential to produce increasingly dynamic conceptualizations of information practice. The simplicity of apps, as well as the sense of structure that they offer, facilitates data creation by extending visual research methods to groups that may be excluded from traditional approaches to data collection. Additionally, the functionality of apps, including the ability to handle rich, multimodal activity, facilitates data management by providing an efficient way to administer and monitor ongoing visual research projects. The examination of the challenges and affordances of mobile apps explicated here provides LIS researchers with the practical guidance needed to take full advantage of visual research methods. As researchers in fields outside of LIS have also demonstrated a lack of attention to mobile apps 
(although see García et al., 2016), this discussion will also provide other academic fields with the level of scrutiny needed for the development of responsible visual research frameworks.

\section{Literature review}

\subsection{Visual research methods}

Visual research methods are defined as "methods which use visual materials of some kind as part of the process of generating evidence in order to explore research questions" (Rose, 2014, p. 25). Encompassing the use of a wide variety of media, including diagrams, cartoons and illustrations as well as photography (Pauwels \& Mannay, 2019), the origins of visual research have been traced back to the disciplines of geography and anthropology, where researchers employed maps, diagrams and photographs to illustrate scientific reports and provide "unbiased" or realistic representations of social science fieldwork (Prosser \& Loxley, 2008; Rose, 2016, p. 15). Representing a positivist approach to visual research, photographic objectivity was challenged in the 1960s by John Collier, who used photographs to reduce misunderstanding between his research team as well as to sharpen participant memories (Collier, 1967). Since critiqued for its "positivist bent" (Harper, 2012, p. 17), Collier's research has nonetheless been credited with paving the way for a reading of images as social and cultural artefacts rather than "explicit, precise, and matterof-fact communication[s]" (Wagner, 2001, p. 7). More recently, these interpretive ideas have become crystallized in Douglas Harper's visual sociology work, which emerges from the premise that seeing is socially constructed (Harper, 2012, p. 4). Gillian Rose has also continued to develop visual research through an examination of visuality and visual culture as well as digital new media (Rose, 2016).

Visual research methods became more prominent in LIS in the early 2000s (see Hicks \& Lloyd, 2018 for a more complete review) when researchers started to employ still photography to record everyday and workplace information tools, sources and spaces (e.g. Hartel, 2006; McKenzie \& Davies, 2012; Pollak, 2017; Thomson, 2010). Since then, researchers have started to center participant-generated visual methods using drawing (e.g. Hartel, 2014), mapping (e.g. Lingel, 2015) and photography (e.g. Julien, Given \& Opryshko, 2013). Visual research has also been embraced within libraries through the work of Foster and Gibbons (2007), who employed mapping and photographic visual research methods within their ethnographic studies of undergraduate research practices. These developments led Pollak (2017), building on the work of Julien, Given \& Opryshko (2013), to characterize visual research methods as taking either an emic (participatory) or etic (non-participatory) approach to data collection. An etic approach to data collection prioritizes the researcher's production and interpretation of images. In contrast, emic data collection methods center the participant's creation and interpretation of images to position visual data as "socially and technically constructed" (Hartel \& Thomson, 2011, p. 2216). These characterizations may further reflect positivist and interpretive approaches to visual data.

\subsection{Photographic visual research methods}

Photography formed the principal method of documentation within both visual anthropology and visual sociology until the 1960s (Prosser \& Loxley, 2008). Recognized for its unobtrusiveness, photography provided social researchers with a useful way to document social change as well as developments over time (Rieger, 1996). Gradually, however, researchers started to grow more reflexive about their role within photographic methods and to question the exclusion of the broader contexts in which images are produced (Rose, 2016, p. 22). These advances led to the development of photo-elicitation and photo-voice methods. Photo-elicitation is defined as the 
insertion of photographic images into a research interview (Harper, 2002, p. 13). Developed in the field of anthropology, photo-elicitation works from the premise that images elicit different types of information than exchanges that are uniquely based upon words (Harper, 2002, p. 13). In contrast, photo-voice forms a type of participatory action research that emerged from work with rural female Chinese communities (Wang, 1999; Wang \& Burris, 1997). With its roots in feminist theory as well as Freirian inquiry (Wang \& Burris, 1997), photovoice has the goal of using photographs to identify problems and solutions to the challenges that communities face (Wang, 1999; Wang \& Burris, 1997). While photovoice and photo-elicitation are often conflated, these contrasting research heritages and orientations call for the need to distinguish between each method's different goals and purposes.

Photographic visual methods have started to become more prominently employed within LIS (Hicks \& Lloyd, 2018). As with visual research, early use of photographic methods focused on the use of pre-existing photographs, which were used to guide and stimulate research interviews (e.g. Baxter et al., 2015). More recently, however, researchers have turned to focus on the contributions that participant-focused visual methods can make to information research. Photoelicitation forms one of the most commonly used methods. Typically employed to assess library community needs (e.g., Neurohr \& Bailey, 2016), photo-elicitation has also been recognized as providing the means through which researchers can access tacit and nuanced ways of knowing (Hicks \& Lloyd, 2018). Photovoice has also been employed within a variety of LIS research projects (e.g. Julien, Given \& Opryshko, 2013). Enabling participants to represent their experiences outside of the research interaction, photovoice has most successfully been used by researchers in projects with a strong emphasis on critical dialogue, for instance with refugees (e.g., Lloyd \& Wilkinson, 2016). LIS researchers are also starting to engage with the broader implications of visual methods through an interrogation of the role that participant-centered photographic methods play in extending the use of grounded theory methods (Hicks, 2018a) and improving the quality of information behavior research (Cox \& Benson, 2017).

\subsection{Digital tools for visual research methods}

Growing interest in visual research methods as well as technological advances means that participant-generated photography has since become increasingly dependent on digital tools. Early studies that employed participatory photographic research methods tended to rely on disposable cameras (Balomenou \& Garrod, 2016). While the use of these simple and cheap devices broadened the scope of participation, researchers also found that the quality of the ensuing photos was poor, particularly in relation to the increasingly sophisticated cameras that could be found in mobile devices (e.g., Lloyd \& Wilkinson, 2016). These considerations consequently catalyzed a reliance on participants' own mobile devices as the means through which images are captured within visual research projects (e.g., Plowman \& Stevenson, 2012; Shankar, O'Brien \& Absar, 2016). Growing usage of mobile devices has also mobilized the development of apps that aim to simplify and streamline data collection within ethnographic research projects, including Speaking Photo (Williams, 2016), the FREE project app (García et al., 2016), and EthnoAlly (Favero \& Theunissen, 2018), as well as EthOS and PixStori, the two apps that form the subject of this research.

EthOS characterises itself as an ethnographic tool that is designed to capture rich details of daily life. Predominantly employed in industry, the app has recently started to become more visible within academia, where it has been used by music therapists to capture video of musical development (Voyajolu, Axon \& Ockelford, 2017), as well as to record researcher notes in a study 
of teacher innovation (Holmes, 2017). In contrast, PixStori is a tool that emerged from oral and digital history projects. The ability to display media means that PixStori has been incorporated into a recent exhibition at the GRAMMY Museum in Los Angeles, California, with attendees invited to create PixStories of their visit and share them with others using the dedicated web portal ("Visitors Share Their Stories," 2016). Within research contexts, the PixStori iOS app has been used in oral history projects (Campbell, 2017) and in a community-based research study employing photo-narrations of meaningful places (Gillette \& Hurley, 2018). PixStori has also been employed in health research as a therapeutic intervention for teens and young adults with cancer (Beaupin et al., 2019) and pediatric palliative caregivers (Levy et al., 2019).

\section{Methodology: Mobile apps for participant-generated photography}

Two recent studies that made use of mobile apps to facilitate participant-generated photography were reviewed in order to identify affordances, challenges, and practical considerations associated with the use of such apps in visual research.

\subsection{EthOS}

EthOS (Ethnographic Observation System) is an iOS and Android app for smartphones or tablet computers (for more information, see https://ethosapp.com/). Described as a mobile ethnographic research platform, EthOS comprises a client-facing app that enables participants to record, keep track of and share media as well as to respond to tasks that a researcher might send them (see Fig. 1). It also incorporates a cloud-based project-management platform that securely stores and organizes data that is captured by participants (see Fig. 2). Handling photos, text, audio and video, EthOS further allows participants to record metadata about their media capture, including notes and comments.

\section{[Insert Fig. 1]}

Fig. 1. Participant's view of the app at the time of the project.

\section{[Insert Fig. 2]}

Fig. 2. Researcher's view of the back-end workspace at the time of the project.

Hicks $(2018 b, 2019)$ employed EthOS in research that explored the information literacy practices of 26 undergraduates who were learning a language overseas. In this study, which examined the role that information interactions play in facilitating transition to and within a new, culturally unfamiliar setting, Hicks explored the activities of 26 undergraduates who were learning a language other than English and who were studying, working or volunteering outside of their home country for a period of at least three months. The focus on an everyday context, as well as the tendency for information literacy research to rely on librarian-defined understandings of practice, meant that photo-elicitation and interviews had already been selected as useful methods to generate situated and participant-generated representations of information activities (Hicks, 2018b). The geographic distances that were involved in this research as well as the lengthy time frame subsequently meant that the EthOS app, which combines a simple interface with project management features, provided a convenient way to facilitate this research approach. High levels 
of smartphone and tablet ownership among college students (Pew Research Center, 2013), the popularity of image social networks such as Snapchat, Instagram and Facebook (Pew Research Center, 2015) and evidence that many students travel abroad with their technology devices (Mikal, 2011) meant that a mobile app was also an appropriate tool for this research.

The visual components of the research were introduced after the first interview. The researcher emailed each participant a link to download the app as well as simple directions about how to use it. At this stage, she engaged each participant in a discussion about privacy issues and the ethics of capturing people's faces and actions as well as questions of personal safety, harm, fairness and justice. This information was also sent to the participant by email. The researcher further reminded participants that photos would only be used in the context of the study and that each participant would retain full ownership of all images, as per the study ethics and the participant information sheet. Participants were subsequently instructed to capture photos of anything that had helped them to settle in or to learn more about their target language and their broader community. Media were then reviewed prior to the second interview, when participants were invited to talk about the five most meaningful images to them. The study's constructivist framing meant that the researcher understood the images to be co-constructed between herself and the participant, as well as forming reflexive interpretations of participant information activities rather than accurate representations of reality. Participants recorded 160 photos for an average of seven per individual. As the project ended, the researcher downloaded all data from the EthOS project management system to her file storage systems before permanently deleting it from the EthOS servers. Participants were also given instructions about how to export their own data from EthOS. Participants who did not want to use EthOS were offered the opportunity to email photographs. This enabled students who did not have a personal mobile device to participate in the research.

\subsection{PixStori}

PixStori is a mobile photography app compatible with iOS devices. Developed by researchers at the University of Buffalo, PixStori combines still images with audio narratives, and also has the option for text-based captions and descriptions (Nealon, 2016; for more information, see http://www.pixstori.com/). The user interface of PixStori is simple and straightforward, using icons to guide the process of either taking a new picture or using an image from the device's camera roll, recording an audio narrative, and adding text in the form of captions and/or descriptions (see Fig. 3). Once a PixStori has been created, it is saved to the device and can then be shared via social media or email. PixStori also offers the option of creating a ShareLink through which users can share their PixStories with others (see Fig. 4). ShareLinks are specific to a project and allow participants to upload their PixStories to a web portal that is only viewable by those who know the web portal URL.

\section{[Insert Fig. 3]}

Fig. 3. Participant's view of the PixStori app during the recording of an audio message.

[Insert Fig. 4] 
Fig. 4. Participant's view of options for sharing completed PixStories, including a research specific ShareLink.

Barriage's (2018a) doctoral dissertation took a child-centered approach to examining the information practices of eighteen 5-7-year-old children within the context of their individual interests. This child-centered approach necessitated the use of methods that "capture the nature of children's lives as lived" (Greene \& Hill, 2005, p. 3) and place the child participants in the position of experts of their own lived experiences (Dahl, 2014). Task-centered activities such as participantgenerated photography offer a means of collecting data that allow for such a child-centered approach (Barriage, 2018b; James, Jenks, \& Prout, 1998). Several methods of data collection were employed in this dissertation research, including a book discussion, poster activity, surveys completed by parents, and participant-generated photography followed by photo-elicitation conversations. The participant-generated photographs were used primarily as a means of eliciting children's perspectives and experiences within this conversational setting, with analytic focus given to the children's descriptions and discussions of their information experiences, rather than the researcher's interpretations of these images.

Determining a means of facilitating the photo-elicitation process with this young population required careful consideration. While young children in the United States are very likely to have access to and experience with mobile devices (Common Sense Media, 2017), EthOS and other similar apps that have been specifically designed for use in a research context rely heavily on the ability to read and write, as well as a certain level of technological literacy. Through pilot testing, the PixStori user interface proved to be effective for use with children in the 5- to 7year age range (Barriage, 2018c). The researcher introduced PixStori to the participants after they had read and discussed a book together and created a poster about their interests and related information activities. The researcher demonstrated how to use the app by creating at least one PixStori with the child during this initial research interaction. Then, the researcher loaned each child an iPod Touch device that had PixStori and the appropriate ShareLink pre-loaded, and gave them a pictorial instruction sheet explaining how to use the app. The researcher asked the participants to take photographs and to record audio narratives explaining what they had photographed and how it related to their interests and their information practices over a one-week period. As participants created PixStories on the loaned devices and uploaded them using the project ShareLink, the PixStories became immediately available to the researcher on a passwordprotected web portal dedicated to the project (see Fig. 5). From this web portal, PixStories could be viewed, downloaded, or deleted. When downloaded, the PixStories included an image file, a text file that included metadata and any captions or comments entered by the user, and an mp4 file. The children created a total of 260 PixStories, an average of 14 PixStories per child. The researcher printed physical copies of the PixStories and discussed these with the children during a subsequent photo-elicitation conversation. The children were given these physical copies to keep.

\section{[Insert Fig. 5]}

Fig. 5. Researcher's view of the project specific PixStori web portal. The text below each image indicates how long ago the images were uploaded and the participant ID number that the participant entered when uploading their PixStories. 


\section{Findings: Affordances, challenges, and practical considerations}

\subsection{Affordances}

\subsubsection{Recordability}

One of the most important affordances of the mobile apps described above is their recordability, or the opportunities that such apps offer to capture a rich array of media. Working with a mobile phone's inbuilt camera, microphone and communication features, EthOS and PixStori allow participants to record and upload photos, audio, text, and, in the case of EthOS, video. While both of the studies examined in this study focused on the use of photos, the variety of media that could be recorded through the use of the apps meant that they can document a range of information activities, including dynamic information processes as well as nuanced and contextual information that is hard to verbalize. At the same time, the ability to assign notes and comments and/or record audio at the point of capture, which creates what García et al. (2016, p.521) label as a "one-stop shop," means that these apps also facilitate the production of contextualized data, something that would be far harder to achieve with basic smartphone functionality (see Tables 1 and 2). The inclusion of screenshots in the EthOS study, an affordance valued in previous research with young people (Volpe, 2019; Yi-Frazier et al., 2015), means that the use of apps also helps to bridge physical and digital information interactions in a way that would, again, be hard to achieve through the use of a traditional standalone camera.

\section{[Insert Table 1]}

[Insert Table 2]

\subsubsection{Immediacy}

A related affordance of apps for participant-generated photography is that of immediacy. As noted above, apps such as EthOS and PixStori offer participants the ability to add text or audio to their images, supplementing the visual with additional contextual information. With more traditional approaches to PhotoVoice or photo-elicitation, participants typically use disposable or digital cameras and then recount the meaning behind the images later when meeting with the researcher. With the use of an app, participants are able to record this meaning immediately, helping to avoid the possibility that they might forget what the picture was of or the meaning behind it when asked later to discuss their images or the event captured (Plowman \& Stevenson, 2012). With both EthOS and PixStori, participants could choose to add this contextual information immediately after capturing their images or at a later time. In the PixStori study, it was evident that many participants recorded their audio messages immediately after taking their photographs. For example, in the background of the audio of several PixStories The Rock created at a hockey arena, the sound of skaters on the ice, hockey sticks hitting pucks, and referees' whistles blowing indicate that he took advantage of this particular affordance in creating his PixStories (as shown, for example, in Table 1). The ability to record metadata was also particularly useful in the EthOS study where some participants took photographs over the course of the six to nine months that they spent overseas (see Table 2).

\subsubsection{Portability}

The portability of smartphones as well as the "embodied visual intimacy" (Palmer, 2012, p. 88) of its handheld touchscreen meant that the use of EthOS and PixStori helped to facilitate access to information activities that take place in a wide range of contexts and locations, including 
those that occur in personal and hard-to-reach spaces such as the bedroom (see Tables 1 and 2). In the EthOS study, for example, the capturing of images related to personal spaces helped to reveal themes related to safety and refuge that would play a prominent role in the final analysis. The portability of using an app on a small mobile device also enabled participants to unobtrusively capture relevant images in settings in which documenting their experiences in other ways may have been difficult or impractical, such as a loud and crowded hockey arena (see Table 1). Additionally, participants were able to capture images between locations, too, including on transport systems (see Tables 1 and 2). As Plowman and Stevenson (2012) note, the ways in which portability affords participants the ability to easily incorporate these research activities into their daily routines is advantageous for both the participant, as it makes their involvement in research less burdensome, and for the researcher, as they are able to gain insight into "unexpected, mundane moments" (Favero \& Theunissen, 2018, p.163) or aspects of participants' lives that might otherwise have remained hidden.

\subsubsection{Visibility}

The EthOS and PixStori apps also offer the affordance of visibility. For participants, the visibility of the app on each participant's device, as well as, in the case of EthOS, the ability to employ push notifications, helped to encourage participation by providing an eye-catching reminder of the research project. The ability to see data as it was created and submitted to the researcher meant that the apps, perhaps, also encouraged participants to submit material from throughout their time in the study, rather than merely from the days immediately preceding the deadline (cf. García et al., 2016, p. 521). For the researcher, the use of the project management platforms associated with these apps additionally allowed for easy and instant monitoring of participant activity on an ongoing basis (as shown in Figs 2 and 5).

\subsubsection{Durability}

The most prominent affordance of the EthOS and PixStori apps is durability, or the persistent and consistent access they offer to participant-generated data for both participants and researchers alike (see Figs 2 and 5). In providing a mechanism through which data can be captured spontaneously as well as over significant periods of time, these apps facilitate access to aspects of everyday information interactions that might otherwise be overlooked. Features that enable the uploading of data that are produced through the phone's native media capture options as well as the storage of media for subsequent upload further supports the usage of such apps amongst participants who may not have sufficient data plans or consistent access to wifi. These apps also reduce the potential for data loss by creating a simple and streamlined mechanism for users to upload media. The inbuilt project management system also benefits the researcher; a removal of the need to consolidate data reduces the possibility of data-entry errors while the standardization of data submission creates consistency by ensuring that all data are received in the same format (cf. García et al., 2016, p. 521). The benefit of a secure and easy-to-use storage system can also be seen in Yi-Frazier et al.'s (2015) Instagram-based photovoice study. Beyond data capture, filtering features within the project management system facilitate the discussion of data during subsequent interviews, while the metadata functionality further helps to remind participants who are being interviewed at a later date of the media as well as the original reasons for which they captured it. In this light, both EthOS and PixStori provide a robust support mechanism for collaboration between researcher and participant as well as facilitating interactive opportunities. 


\subsection{Challenges and Practical Considerations}

\subsubsection{Data Security \& Storage}

One challenge related to the use of apps such as EthOS and PixStori is data security and storage. The use of a third-party cloud-based app for research necessarily raises a number of issues related to how study data are processed and saved. For example, EthOS' security policy, which was provided to the author upon request, details that data captured using the EthOS app are stored at a secure, access-controlled data center that provides a high level of network, host, physical and environmental security. Data and file attachments are encrypted, and EthOS employees cannot access this data unless they are required to do so by law. While these provisions are comparable with other digital tools that may be employed during research, for example Dropbox, the researcher chose to reduce these potential risks even further by deleting data from the EthOS project management system after the research terminated and reminding participants how to download their own data should they wish to do so. The researcher also reached out to the parent company, Everyday Lives Ltd, who talked through some of these concerns. However, the storage of EthOS data on the Amazon Web Service (AWS) infrastructure located within the United States may prove problematic for researchers from other countries, as there are important legal implications related to cross-border data storage and privacy (de Jong-Chen, 2015; Woods, 2018).

\subsubsection{Device Failures}

An unexpected challenge of the EthOS study related to the use of participants' own phones. While participants did not demonstrate any problems using EthOS, the context for this research meant that the study's use of an app posed a number of issues. Perhaps unsurprisingly, lost or damaged phones proved to be one of the most common complications that participants faced during this study. One student described how they lost all their photos when the computer on which they were backing up their photos crashed, although they were able to describe the images in lieu of showing them to the researcher. Along the same lines, security concerns meant that two students decided not to travel overseas with a smartphone, preferring, instead, to rely on what they termed as a 'festival' phone, or an older and more basic model of phone that would be less likely to be stolen, as well as less expensive to replace. A handful of participants also ran into issues when they came to download the app; as financially insecure students, an inability to afford an upgrade to their phone meant that they did not have enough memory on their phone to install the EthOS app. These issues demonstrate the complexity of carrying out research in overseas locations as well as with populations who may not enjoy access to the latest technological developments.

\subsubsection{App Failures}

In addition to technological failures associated with the devices used by participants to capture data, failures of the app and any associated online collection mechanisms can also be a cause for concern. In the PixStori study, the researcher experienced a temporary technical problem with the web portal that made it appear as if all data collected up to that point had been lost. Fortunately the issue was quickly rectified upon contact with the parent company, Talking Pictures LLC, and only impacted the researcher's ability to view data collected in the web portal temporarily. The technical problem did not result in the loss of any previously existing data nor hinder participants' ability to continue to generate new data. This issue, though, highlights the challenges associated with relying on a third party for facilitation of the data collection process. If the technical problem had been more significant, all data collected for this project via the PixStori web portal could have been lost. A second technical difficulty encountered in the PixStori study 
involved video playback issues. A handful of PixStories (three of the 260 PixStories created by participants for the study) would not play once uploaded to the web portal. While the image components of the PixStories were still accessible, the accompanying audio recordings were not. This was a problem with the web portal specifically, and not with the devices, and the audio recordings were recoverable from the iOS devices. Stringent protocols for backing up data on a regular basis may help to mitigate this particular challenge. An additional fail-safe in the context of the children's interests study was that the data were saved on the iPods loaned to the children for the purposes of the study, in addition to being saved in the web portal. Once participants returned their devices, the researcher was able to access all PixStories created during the study period. This option would not have been possible if participants had generated data using their own devices.

\subsubsection{User Instruction}

An additional consideration that researchers must consider when incorporating apps to facilitate participant-generated photography is that of user instruction (Garcia et al., 2016). While EthOS and PixStori were both fairly intuitive and easy for participants to use, not all users will find them to be so. Additionally, participants may require instruction regarding the specific ways in which researchers expect them to make use of the apps for research purposes. In both the EthOS and PixStori studies, the researchers provided the participants with instructions on how to create images and share them with the researcher. In addition, in the PixStori study the researcher demonstrated how to use the app by creating at least one PixStori with each child before sending them home with the iPod for the duration of the study. In the PixStori study, participants predominantly came from highly educated and high-income households; they all had access to technology in their homes, and all were comfortable using touch-screen devices. Similarly, participants in the EthOS study used their own devices in completing the research activities, and therefore had experience using these devices generally and apps more specifically. The amount of instruction that they needed might have been different if they were not already comfortable and accustomed to using such technology in their daily lives.

\subsubsection{Cost}

The impact of using apps in research on project cost is largely dependent on the specific app being used, as well as the population under study. As with any research endeavor, there are a variety of costs and cost-savings that must be weighed before determining the feasibility of implementing a particular app. In the past, researchers making use of participant-generated photography have incurred costs related to purchasing enough disposable or digital cameras for participant use, as well as the costs associated with developing film or printing physical copies of digital images. When compared to these methods, the use of apps has the potential to be a "costeffective" approach to data collection (García et al., 2016, p. 509). For example, for research that focuses on individuals who are likely to own their own smartphones, researchers are not required to provide these or alternative devices to their participants for data collection purposes. Using an app that has already been developed also saves researcher time and effort in designing an equivalent data collection mechanism. The resultant savings of the researcher's time may also, as García et al. (2016, p. 519) point out, make the financial costs of the app more worthwhile.

In the EthOS study, the use of this app incurred several costs that would not typically be budgeted for within visual research using more traditional photographic methods. As a proprietary app, EthOS charges a fee for use of its app, providing pricing options per day or per participant. However, they also offer a reduced rate for students and suggest that they may be able to provide 
free usage for unfunded academic or student projects (EthOS, n.d.). In the PixStori study, while the app and associated web portal were free to use, the researcher purchased multiple iPod Touch devices to loan to the participants in order to enable participation by children who did not own their own iOS device. Additionally, the researcher provided each participant with physical copies of their images; in this case, use of the app did not eliminate the expense of photo printing. Additional costs for both the EthOS and PixStori studies included participant compensation, which was appropriate in both studies due to the time participants invested in the research, as well as an investment of the researchers' time in learning how to use the app and associated data management tools.

\subsubsection{Ethical Considerations}

One of the most common challenges of visual research more generally refers to the researcher's ethical considerations and obligations (Rose, 2016), and the use of an app for research only heightens these concerns. The commonplace role that mobile phones and apps play in everyday life as well as increasingly photo-centered communication norms (Pew Research Center, 2015) means that it is vitally important to discuss questions of privacy as well as personal safety and harm with participants. This discussion was also particularly necessary within the context of the EthOS study given that participants would be taking photographs in settings that might not share Western norms of photography. Questions of privacy also meant that this study limited media capture to the use of photography and still images, even though EthOS has the capability to store audio and video files. The need to seek permission from people who are featured within media, as well as fears that the app could be used to inadvertently capture private conversations proved to be challenging to overcome, although video-mediated research is increasingly starting to become more visible within LIS research and beyond (e.g., Barriage \& Searles, 2015; Bhatt \& de Roock, 2013; Given, Cantrell Winkler, Willson, Davidson, Danby \& Thorpe, 2016; Lundh, 2011; Polkinghorne, 2018). Issues were also muddied within this research due to the number of laws about filming in public places around the world (Mok, Cornish \& Tarr, 2015, p. 317). See Table 3 for an overview of the findings.

[Insert Table 3]

\section{Research Agenda}

An exploration of the roles that apps play within participant-centered photographic research methods raises a number of avenues for future research (see Table 4).

\section{[Insert Table 4]}

\subsection{Effects of mobile apps on data quality}

In terms of participant-generated photography, this study illustrates the need for research that compares the use of mobile apps to other established methods of photo-elicitation. The move from print to digital photographic practices has already been credited with creating more spontaneous personal photography, as well as enabling a greater focus on the everyday and the mundane (Rubinstein \& Sluis, 2008, p. 9). Further research should build upon these ideas to explore whether the use of a mobile app impacts a study's participant retention rate or participants' experiences of engaging in research in some other way (see Plowman \& Stevenson, 2012; cf. Garcia et al., 2015). Future research could also examine the specific images that participants take 
within photo-elicitation studies to determine whether the use of an app impacts the scope of photos and media captured as part of the study. Research could further investigate whether the employment of mobile apps changes or helps to increase the contextualization provided for each image compared to studies that rely on data that is sent through email or similar. Moving beyond apps, research should also examine the role of image-based social networks such as Pinterest and Instagram within photo-elicitation studies. While these tools are used extensively by certain research participant demographics (Pew Research Center, 2018a; Pew Research Center, 2018b), there has been a lack of engagement with the ways in which they could be adapted for use within participatory photographic research methods (although see Volpe, 2019; Yi-Frazier et al., 2015).

\subsection{Co-production of knowledge}

The use of apps such as EthOS and PixStori also demonstrate the importance of continuing to reflect upon the ways in which LIS researchers both construct and access their field of study. As Beaulieu (2010) points out, increasingly distributed systems of knowledge production mean that researcher co-location can no longer be the only requisite for ethnographic fieldwork. Instead, researcher co-presence, which foregrounds interactions and relationships rather than (necessarily) physical proximity, is increasingly being considered as a way to facilitate contiguity as well as reflexive and ethical accountability (Beaulieu, 2010, p. 460). Future research should examine the ways in which apps such as EthOS and PixStori facilitate the production of co-presence between researcher and participant while further reflecting on how the decentering of space and the ocularcentric concept of testimony (Beaulieu, 2010, p. 457) impacts information research. The ability to capture and create multimedia means that future research should also explore whether apps such as EthOS and PixStori could replace the use of manual diary and check-in research methods within LIS. As Cox, McKinney and Goodale (2017, p. 186) point out, paper diaries can be cumbersome as well as difficult to use outside the home or on the move. And, while digital diary and check-in tools have become more prevalent, the need for sustained diligence means that data-loss is common (Corti, 1993). A reliance on email reminders could further disenfranchise users who do not use this technology as frequently as other groups, such as teens (Perez, 2016). In contrast, the ability to push notifications as well as to create a dedicated phone-based portal for a project means that research should explore whether apps, which store text as well as multimedia, could help to improve response rates amongst certain user groups as well as to provide a more reliable platform for this type of research.

\subsection{Scope of information research}

Future research should also examine the role that apps can play in extending the scope of information research. The ability to record audio as well as photographs and texts, for example, means that the use of apps such as EthOS and PixStori could build upon the recent focus on the body within LIS research (Lloyd, 2010) to explore sensory aspects of information activities in more detail, including working with voice audio as research data in itself rather than merely as "a precursor to transcription" (Gallagher, 2019, p. 1). Sound has not often formed the focus of LIS research, which has tended to emphasize text-based formats of information (Lloyd, 2010). However, as automated voices become employed as coercive forces within urban settings (Power, 2014) and the use of voice-controlled assistants such as Alexa continues to rise (Pew Research Center, 2017), it is clear that sound as well as speech play an important role within everyday information interactions. Future research could explore the important role that apps, which provide simple and intuitive access to the audio-recording features on a mobile device, could play in 
facilitating this new area of study. Along the same lines, studies could also specifically explore the role that apps could play within health information research; as Cox et al. (2017) point out, the ability to track data means that apps open up information research to a range of new ways to capture and analyze health interactions. At the same time, concerns over surveillance as well as increased understanding of the role that m-health apps can play in contributing to "techno-utopian" (Morley \& Floridi, 2019) narratives of patient empowerment means that scholarship should also examine the ethical implications of adopting apps for these research purposes. Lastly, the rise of mapping apps means that future research could also examine the role that these tools play in creating qualitative responses to places and built environments (cf. Headrick Taylor, 2017, also see Favero \& Theunissen, 2018).

\subsection{Mobility and information practice}

Beyond photo-elicitation methods, this study raises a number of questions about the impact of mobility upon information practices. While LIS research has engaged with concepts of space and place (e.g., Savolainen, 2006), far less attention has been paid to the ways in which expanding mobility as well as possibilities for learning on the move shape emplaced understandings. As Headrick Taylor (2017, p. 534) points out, the success of games such as Pokemon Go and workout mapping tools such as MapMyRun demonstrate that mobile apps are being used "to engage with places in a personally meaningful way" as well as to address practical needs. Future research should examine how apps such as EthOS and PixStori support the creation of "bodies in place" (p. 538) as well as interconnections with affective experience, social justice and community change. Along the same lines, research should also examine mobile apps as material objects. While studies have explored the impact of smartphones (e.g., Howard \& Bussell, 2018) and tablets (e.g., Burford \& Park, 2014) upon information activities, there has been little focus on the ways in which apps, as physical artefacts, enable and constrain the enactment of information practices. Future research should examine the sociomaterial dimensions of mobile information practices in more detail, including the ways in which apps function as boundary (Star \& Griesemer, 1989) or epistemic objects (Knorr Cetina, 2001) that shape or coordinate information activities.

\section{Conclusion}

As the use of visual research methods continues to grow within LIS, it is vital that researchers continue to think carefully about the ways in which methods that were established in a pre-digital age are recreated and used within technology rich environments. Along these lines, this study has provided a detailed and critical interrogation of the role that mobile apps can play within visual research methods. Noting that a failure to examine apps in any great detail has limited the researcher's ability to recognize their value, this study extends visual research by illustrating how the use of EthOS and PixStori resolves many of the logistical and practical challenges of working with participant-generated photographic data. At the same time, the recognition that visual research is subject to several important ethical considerations means that this study also establishes a useful framework through which LIS researchers can make more informed decisions about the role that apps can play within image-centered methodologies. Importantly, the study further sets the scene for the continued growth of visual and participatory research through the establishment of a research agenda that pushes at the boundaries of the complex information worlds in which we live. 


\section{References}

Barriage, S. (2018a). Examining the red thread of information in young children's interests: $A$ child-centered approach to understanding information practices (Unpublished doctoral dissertation). Rutgers, The State University of New Jersey, New Brunswick, NJ.

Barriage, S. (2018b). Task-centered activities as an approach to data collection in research with children and youth. Library \& Information Science Research, 40(1), 1-8. doi:10.1016/j.lisr.2018.01.001

Barriage, S. (2018c, February). Young children's individual interests and information practices: Pilot study findings and lessons learned. Poster presented at the ALISE 2018 Annual Conference, Denver, CO.

Barriage, S., \& Searles, D. K. (2015). Astronauts and sugar beets: Young girls' information seeking in family interactions. Proceedings of the Association for Information Science \& Technology, 52(1), 1-10. doi:10.1002 /pra2.2015.145052010027

Balomenou, N., \& Garrod, B. (2016). A review of participant-generated image methods in the social sciences. Journal of Mixed Methods Research, 10, 335-351. doi: $10.1177 / 1558689815581561$

Baxter, G., Cooper, K., Gray, D., Reid, P., Vergunst, J., \& Williams, D. (2015). The use of photo elicitation to explore the role of the main street in Kirkwall in sustaining cultural identity, community, and a sense of place. Aberdeen Business School Working Paper Series, 8(1). Retrieved November 1, 2019 from https://openair.rgu.ac.uk/handle/10059/1185

Beaulieu, A. (2010). From co-location to co-presence: Shifts in the use of ethnography for the study of knowledge. Social Studies of Science, 40, 453-470. doi:10.1177/0306312709359219

Beaupin, L.K., Pailler, M.E., Brewer-Spritzer, E., Kishel, E., Grant, P.C., Depner, R.M., .. . Breier, J.M. (2019). Photographs of meaning: A novel social media intervention for adolescent and young adult cancer patients. Psycho-Oncology, 28, 198-200. doi:10.1002/pon.4896

Bhatt, I., \& de Roock, R. (2013). Capturing the sociomateriality of digital literacy events. Research in Learning Technology 21(1), 1-19. doi:10.3402/rlt.v21.21281

Buchanan, S., Jardine, C. \& Ruthven, I. (2018). Developing information literacy in dependent and disadvantaged circumstances: A transitional approach in the digital health context. In S. Kurbanoğlu, J. Boustany, S. Špiranec, E. Grassian, D. Mizrachi, \& L. Roy (Eds.), Information literacy in the workplace (pp.409-418). Cham, Switzerland: Springer.

Burford, S. \& Park, S. (2014). The impact of mobile tablet devices on human information behaviour. Journal of Documentation, 70, 622-639. doi:10.1108/JD-09-2012-0123

Campbell, R. (2017). PixStori [Review]. Oral History Review, 44(1), 117-119. doi:10.1093/ohr/ohx017

Collier, J. (1967). Visual anthropology: Photography as a research method. New York, NY: Holt, Rinehart and Winston. 
Common Sense Media. (2017). The Common Sense census: Media use by kids age zero to eight. Retrieved from https:/www.commonsensemedia.org/sites/default/files/ uploads/ research/csm_zerotoeight_fullreport_release_2.pdf

Corti, L. (1993). Using diaries in social research. Social Research Update, (2). Retrieved from http://sru.soc.surrey.ac.uk/SRU2.html

Cox, A., \& Benson, M. (2017). Visual methods and quality in information behaviour research: The cases of photovoice and mental mapping. Information Research, 22(2), 749. Retrieved November 1, 2019 from http://informationr.net/ir/22-2/paper749.html

Cox, A.M., McKinney, P. \& Goodale, P. (2017). Food logging: An information literacy perspective. Aslib Journal of Information Management, 69, 184-200. doi:10.1108/AJIM12-2016-0208

Dahl, T.I. (2014). Children as researchers: We have a lot to learn. In G.B. Melton, A. Ben-Arieh, J. Cashmore, G.S. Goodman, \& N.K. Worley (Eds.), The SAGE handbook of child research (pp. 593-618). Los Angeles, CA: Sage.

de Jong-Chen, J. (2015). Data sovereignty, cybersecurity, and challenges for globalization. Georgetown Journal of International Affairs, 112-122.

Favero, P.S., \& Theunissen, E. (2018). With the smartphone as field assistant: Designing, making, and testing EthnoAlly, a multimodal tool for conducting serendipitous ethnography in a multisensory world. American Anthropologist, 120, 163-167. doi:10.1111/aman.12999

Foster, N.F., \& Gibbons, S. (2007). Studying students: The Undergraduate Research Project at the University of Rochester. Chicago, IL: Association of College and Research Libraries.

Gallagher, M. (2019). Voice audio methods. Qualitative Research. Advance online publication. doi: $10.1177 / 1468794119867549$

García, B., Welford, J., \& Smith, B. (2016). Using a smartphone app in qualitative research: The good, the bad and the ugly. Qualitative Research, 16, 508-525. doi: $10.1177 / 1468794115593335$

Gillette, M.B., \& Hurley, A. (2018). Vision, voice, and the community landscape: The Missouri Place Stories pilot project. Landscape \& Urban Planning, 173, 1-8. doi:10.1016/j.landurbplan.2018.01.005

Given, L.M., Cantrell Winkler, D., Willson, R., Davidson, C., Danby, S., \& Thorpe, K. (2016). Parents as coresearchers at home: Using an observational method to document young children's use of technology. International Journal of Qualitative Methods, 15(1), 1-9. doi:10.1177/1609406915621403

Greene, S., \& Hill, M. (2005). Researching children's experience: Methods and methodological issues. In S. Greene \& D. Hogan (Eds.), Researching children's experience: Methods and approaches (pp. 1-21). Thousand Oaks, CA: Sage.

Harper, D. (2002). Talking about pictures: A case for photo elicitation. Visual Studies, 17(1), 1326. doi:10.1080/14725860220137345

Harper, D. (2012). Visual sociology. London, England: Routledge.

Hartel, J. (2006). Information activities and resources in an episode of gourmet cooking. Information Research, 12(1), 282. Retrieved November 1, 2019 from http://informationr.net/ir/12-1/paper282

Hartel, J. (2014). An arts-informed study of information using the draw-and-write technique. Journal of the Association for Information Science and Technology, 65, 1349-1367. doi:10.1002/asi.23121 
Hartel, J., \& Thomson, L. (2011). Visual approaches and photography for the study of immediate information space. Journal of the American Society for Information Science and Technology, 62, 2214-2224. doi:10.1002/asi.21618

Headrick Taylor, K. (2017). Learning along lines: Locative literacies for reading and writing the city. Journal of the Learning Sciences, 26, 533-574. doi:10.1080/10508406.2017.1307198

Hicks, A. (2018a). Developing the methodological toolbox: Grounded theory, information literacy and visual research. Library and Information Science Research, 40, 194-200. doi:10.1016/j.lisr.2018.09.001.

Hicks, A. (2018b). The theory of mitigating risk: Information literacy and language-learning in transition (Published doctoral dissertation). University of Borås, Borås, Sweden. Retrieved November 1, 2019 from http://urn.kb.se/resolve?urn=urn:nbn:se:hb:diva-15000

Hicks, A. (2019). Mitigating risk: Mediating transition through the enactment of information literacy practices. Journal of Documentation, 75(5), 1190-1210. doi:10.1108/JD-11-20180184

Hicks, A., \& Lloyd, A. (2018). Seeing information: Visual methods as entry points to information practices. Journal of Librarianship and Information Science, 50, 229-238. doi:10.1177/0961000618769973

Holmes, T. (2017). Perceptions in a changing world: Teachers' attitudes towards the implementation of educational innovations with a focus on social and emotional learning (Unpublished doctoral thesis). Kennesaw State University, Kennesaw, GA.

Howard, M., \& Bussell, H. (2018). Habituated: A Merleau-Pontian analysis of the smartphone. Library Trends, 66, 267-288. doi:10.1353/lib.2018.0003

James, A., Jenks, C., \& Prout, A. (1998). Theorizing childhood. Cambridge, England: Polity Press.

Julien, H., Given, L.M., \& Opryshko, A. (2013). Photovoice: A promising method for studies of individuals' information practices. Library \& Information Science Research, 35, 257-263. doi:10.1016/j.lisr.2013.04.004

Knorr Cetina, K. (2001). Objectual practice. In T. R. Schatzki, K. Knorr Cetina, \& E. von Savigny (Eds.), The practice turn in contemporary theory (pp. 175-188). London, England: Routledge.

Levy, K., Grant, P.C., Depner, R.M., Tenzek, K.E., Pailler, M.E., Beaupin, L.K., . . Byrwa, D.J. (2019). The Photographs of Meaning Program for pediatric palliative caregivers: Feasability of a novel meaning-making intervention. American Journal of Hospice \& Palliative Medicine, 36, 557-563. doi:10.1177/1049909118824560

Lingel, J. (2015). Information practices of urban newcomers: An analysis of habits and wandering. Journal of the Association for Information Science and Technology, 66, 1239-1251. doi:10.1002/asi.23255

Lloyd, A. \& Wilkinson, J. (2016). Knowing and learning in everyday spaces (KALiEds): Mapping the information landscape of refugee youth learning in everyday spaces. Journal of Information Science, 42, 300-312. doi:10.1177/0165551515621845

Lloyd, A. (2010). Information literacy landscapes: Information literacy in education, workplace and everyday contexts. Oxford, England: Chandos Publishing.

Lundh, A. (2011). Doing research in primary school: Information activities in project-based learning (Published doctoral dissertation). University of Borås, Borås, Sweden. Retrieved November $\quad 1$, $2019 \quad$ from $\quad$ http://hb.divaportal.org/smash/record.jsf?pid=diva2\%3A876983\&dswid=-8450 
McKenzie, P.J. \& Davies, E. (2012). Genre systems and 'keeping track' in everyday life. Archival Science, 12, 437-460. doi:10.1007/s10502-012-9174-5

Mikal, J. (2011). When social support fits into your luggage: Online support seeking and its effects on the traditional study abroad experience. Frontiers: The Interdisciplinary Journal of Study Abroad, 21, 17-40. doi: 10.36366/frontiers.v21i1.302

Mok T.M., Cornish, F., \& Tarr, J. (2015). Too much information: Visual research ethics in the age of wearable cameras. Integrative Psychological and Behavioral Science, 49, 309-322. doi:10.1007/s12124-014-9289-8.

Morley, J., \& Floridi, L. (2019). Enabling digital health companionship is better than empowerment. The Lancet Digital Health, 1(4), e155-e156. doi:10.1016/S25897500(19)30079-2

Nealon, C. (2016, February 8). PixStori app merges social history with Instagram-like photos. UB Reporter. Retrieved August 13, 2016, from http://www.buffalo.edu/ubreporter/stories /2016/02/frisch_pixstori.html

Neurohr, K.A. \& Bailey, L.E. (2016). Using photo-elicitation with Native American students to explore perceptions of the physical library. Evidence Based Library and Information Practice, 11(2), 56-73. doi:10.18438/B8D629

Palmer, D. (2012). iPhone photography: Mediating visions of social space. In L. Hjorth, J. Burgess, \& I. Richardson (Eds.), Studying mobile media: Cultural technologies, mobile communication and the iPhone (pp. 85-97). Abingdon, England: Routledge.

Pauwels, L., \& Mannay, D. (2019). The SAGE handbook of visual research methods. London, England: SAGE.

Perez, S. (2016). Email is dying among mobile's youngest users. TechCrunch. Retrieved November 1, 2019 from https://techcrunch.com/2016/03/24/email-is-dying-amongmobiles-youngest-users/

Pew Research Center (2013). Smartphone ownership 2013. Retrieved November 1, 2019 from http://www.pewinternet.org/2013/06/05/smartphone-ownership-2013/

Pew Research Center (2015). Teens, social media, and technology overview 2015. Retrieved November 1, 2019 from http://www.pewinternet.org/2015/04/09/teens-social-mediatechnology-2015/

Pew Research Center (2017). Nearly half of Americans use digital voice assistants, mostly on their smartphones. Retrieved November 1, 2019 from http://www.pewresearch.org/fact$\operatorname{tank} / 2017 / 12 / 12 /$ nearly-half-of-americans-use-digital-voice-assistants-mostly-on-theirsmartphones/

Pew Research Center (2018a). Teens, social media \& technology 2018. Retrieved November 1, 2019 from https://www.pewresearch.org/internet/2018/05/31/teens-social-mediatechnology- 2018/

Pew Research Center (2018b). Who uses Twitter, Pinterest and Snapchat? Retrieved November 1, 2019 from https://www.pewresearch.org/internet/chart/who-uses-pinterest-snapchatyoutube-an

d-whatsapp/

Pew Research Center (2019). Smartphone ownership is growing rapidly around the world, but not always equally. Retrieved November 1, 2019 from https://www.pewresearch.org/global/2019/02/05/ smartphone-ownership-is-growingrapidly-around-the-world-but-not-always-equally/ 
Plowman, L., \& Stevenson, O. (2012). Using mobile phone diaries to explore children's everyday lives. Childhood, 19, 539-553. doi:10.1177/0907568212440014

Polkinghorne, S. (2018). Going GoPro: Integrating a wearable camera into qualitative information research. Proceedings of the Association for Information Science and Technology, 55, 881882. doi:10.1002/pra2.2018.14505501158

Pollak, A. (2017). Visual research in LIS: Complementary and alternative methods. Library \& Information Science Research, 39, 98-106. doi:10.1016/j.lisr.2017.04.002

Power, N. (2014). Soft coercion, the city, and the recorded female voice. In M. Gandy \& Nilson, B. (Eds.), The acoustic city (pp. 23-26). Berlin, Germany: JOVIS Verlag GmbH.

Prosser, J., \& Loxley, A. (2008). Introducing visual methods. National Center for Research Methods. Retrieved Noveber 1, 2019 from http://eprints.ncrm.ac.uk/420/

Rieger, J.H. (1996). Photographing social change. Visual Studies, 11(1), 5-49. doi:10.1080/14725869608583755

Rose, G. (2014). On the relation between 'visual research methods' and contemporary visual culture. The Sociological Review, 62, 24-46. doi:10.1111/1467-954X.12109

Rose, G. (2016). Visual methodologies: An introduction to researching with visual materials (4th ed.). Thousand Oaks, CA: Sage

Rubinstein, D., \& Sluis, K. (2008). A life more photographic: Mapping the networked image. Photographies, 1(1), 9-28. doi:10.1080/17540760701785842

Savolainen, R. (2006). Spatial factors as contextual qualifiers of information seeking. Information Research, 11(4), 261. Retrieved November 1, 2019 from http://InformationR.net/ir/114/paper261.html

Star, S.L., \& Griesemer, J.R. (1989). Institutional ecology, translations' and boundary objects: Amateurs and professionals in Berkeley's Museum of Vertebrate Zoology, 1907-39. Social Studies of Science, 19, 387-420. doi:10.1177/030631289019003001

Thomson, L.E.A. (2010). Information in the home office: An ethnographic study of space, content, management, and use. (Unpublished master's thesis). University of Toronto, Toronto, ON.

Visitors share their stories live at the GRAMMY Museum. (2016, April 26). Retrieved August 13, 2016 from http:/www.pixstori.com/visitors-share-their-stories-live-at-the-grammymuseum/

Volpe, C.R. (2019). Digital diaries: New uses of PhotoVoice in participatory research with young people. Children's Geographies, 17, 361-370. doi:10.1080/14733285.2018.1543852

Voyajolu, A., Axon, R., \& Ockelford, A. (2017) Researching the musical engagement of young children with retinopathy of prematurity. Proceedings of the 8th Conference of the European Network of Music Educators and Researchers of Young Children, 294-301. Retrieved

from http://meryc.co.uk/MERYC_Eu_Conference_Proceedings_Cambridge_2017.pdf

Wagner, J. (2001). Does image-based field work have more to gain from extending or from rejecting scientific realism? An essay in review. Visual Studies, 16(2), 7-21. doi:10.1080/14725860108583832

Wang, C. (1999). Photovoice: A participatory action research strategy applied to women's health. Journal of Women's Health, 8, 185-192. doi:10.1089/jwh.1999.8.185

Wang, C., \& Burris, M.A. (1997). Photovoice: Concept, methodology, and use for participatory needs assessment. Health Education \& Behavior, 24, 369-387. doi:10.1177/109019819702400309 
Woods, A.K. (2018). Litigating data sovereignty. Yale Law Journal, 128, 328-406.

Yi-Frazier, J. P., Cochrane, K., Mitrovich, C., Pascual, M., Buscaino, E., Eaton, L., Panlasigui, N., Clopp, B., \& Malik, F. (2015). Using Instagram as a modified application of photovoice for storytelling and sharing in adolescents with type 1 diabetes. Qualitative Health Research, 25, 1372-1382. doi:10.1177/1049732315583282 